\title{
A bottom-up approach of stochastic demand allocation in water quality modelling
}

\author{
E. J. M. Blokker ${ }^{1,2}$, J. H. G. Vreeburg ${ }^{1,2}$, H. Beverloo ${ }^{1}$, M. Klein Arfman ${ }^{3}$, and J. C. van Dijk ${ }^{2}$ \\ ${ }^{1}$ KWR Watercycle Research Institute, P.O. Box 1072, 3430 BB Nieuwegein, The Netherlands \\ ${ }^{2}$ Delft University of Technology, Department of Civil Engineering and Geosciences, P.O. Box 5048, \\ 2600 GA Delft, The Netherlands \\ ${ }^{3}$ PWN Water Supply Company North-Holland, P.O. Box 2113, 1990 AC, Velserbroek, The Netherlands \\ Received: 10 December 2009 - Published in Drink. Water Eng. Sci. Discuss.: 4 January 2010 \\ Revised: 22 March 2010 - Accepted: 8 April 2010 - Published: 15 April 2010
}

\begin{abstract}
An "all pipes" hydraulic model of a drinking water distribution system was constructed with two types of demand allocations. One is constructed with the conventional top-down approach, i.e. a demand multiplier pattern from the booster station is allocated to all demand nodes with a correction factor to account for the average water demand on that node. The other is constructed with a bottom-up approach of demand allocation, i.e., each individual home is represented by one demand node with its own stochastic water demand pattern. This was done for a drinking water distribution system of approximately $10 \mathrm{~km}$ of mains and serving ca. 1000 homes. The system was tested in a real life situation.

The stochastic water demand patterns were constructed with the end-use model SIMDEUM on a per second basis and per individual home. Before applying the demand patterns in a network model, some temporal aggregation was done. The flow entering the test area was measured and a tracer test with sodium chloride was performed to determine travel times. The two models were validated on the total sum of demands and on travel times.

The study showed that the bottom-up approach leads to realistic water demand patterns and travel times, without the need for any flow measurements or calibration. In the periphery of the drinking water distribution system it is not possible to calibrate models on pressure, because head losses are too low. The study shows that in the periphery it is also difficult to calibrate on water quality (e.g. with tracer measurements), as a consequence of the high variability between days. The stochastic approach of hydraulic modelling gives insight into the variability of travel times as an added feature beyond the conventional way of modelling.
\end{abstract}

\section{Introduction}

The goal of drinking water companies is to supply their customers with good quality drinking water $24 \mathrm{~h}$ per day. With respect to water quality, the focus has for many years been on drinking water treatment. Recently, interest in the water quality of a drinking water distribution system (DWDS) has been growing. Water age is an important aspect of water quality in a DWDS as it influences disinfectant residual, disinfection by-products, nitrification, bacterial regrowth, corrosion, sedimentation, temperature, taste and odour (EPA, 2002). More specifically, the maximum water age (or travel time) is most important (Machell et al., 2009).

The key element of a water quality model for a DWDS is a detailed hydraulic model (Slaats et al., 2003; Vreeburg, 2007), which not only takes into account the maximum flows but also the flows at all other time steps (Powell et al., 2004; Slaats et al., 2003; Vreeburg and Boxall, 2007). A hydraulic model with an accurate simulation of the occurrence of turbulent and laminar flow and stagnant water is needed. Therefore, knowledge of the water demand on a detailed level is essential. 
Table 1. Pipe diameters and materials in network.

\begin{tabular}{rccc}
\hline Diameter (mm) & \multicolumn{2}{c}{ Length $(\mathrm{km})$} & Volume $\left(\mathrm{m}^{3}\right)$ \\
& CI & PVC & \\
\hline 100 & & 1.4 & 7.8 \\
100 & 1.3 & 0.6 & 14.8 \\
150 & 3.4 & 1.1 & 79.1 \\
180 & & 0.4 & 12.9 \\
225 & 0.9 & & 35.0 \\
\hline total & 5.6 & 3.5 & 149.7 \\
\hline
\end{tabular}

This requires a different approach in demand allocation, where the demands show less (auto)-correlation and are determined on smaller temporal and spatial scales (Blokker et al., 2008) than the conventional "top-down" approach of demand allocation (Blokker et al., 2008). Here, top-down demand allocation means that a demand multiplier pattern (DMP; e.g. measured at the pumping station) is allocated to the demand nodes with a correction factor to account for the average water demand on that node, thereby applying strongly correlated water demand patterns on all nodes. A different way is to use a "bottom-up" approach of demand allocation. This means that stochastic water demand patterns are modelled for each individual home and a unique water demand pattern is constructed for each demand node by summation of the individual household water demand patterns. In the traditional approach of top-down demand allocation the cross-correlation is assumed to be equal to 1 and the autocorrelation is usually high because a time step of $15 \mathrm{~min}$ or $1 \mathrm{~h}$ is used. A cross-correlation of 1 results in a limited number of flow direction reversals in a network model. A high auto-correlation means that the flow over the day is relatively constant and the model will show no periods with stagnant water and possibly a limited period of turbulent flow. In case the actual flows are not strongly correlated, flow direction reversals and periods of stagnancy and turbulent flows will occur. A traditional approach in demand allocation may therefore underestimate maximum travel times and dispersion.

In this paper the top-down and bottom-up demand allocations in an "all pipes" hydraulic model are compared with respect to the resulting flow patterns and water age as measured in a tracer study. The bottom-up demand allocation was done with the use of the end-use model SIMDEUM (Blokker et al., 2010).

\section{Methods and materials}

A distribution network of about $10 \mathrm{~km}$ of mains and 1000 homes was selected as a test area. In this network, the total flow was measured and a tracer study was performed to determine the water age at four locations in the network. An "all

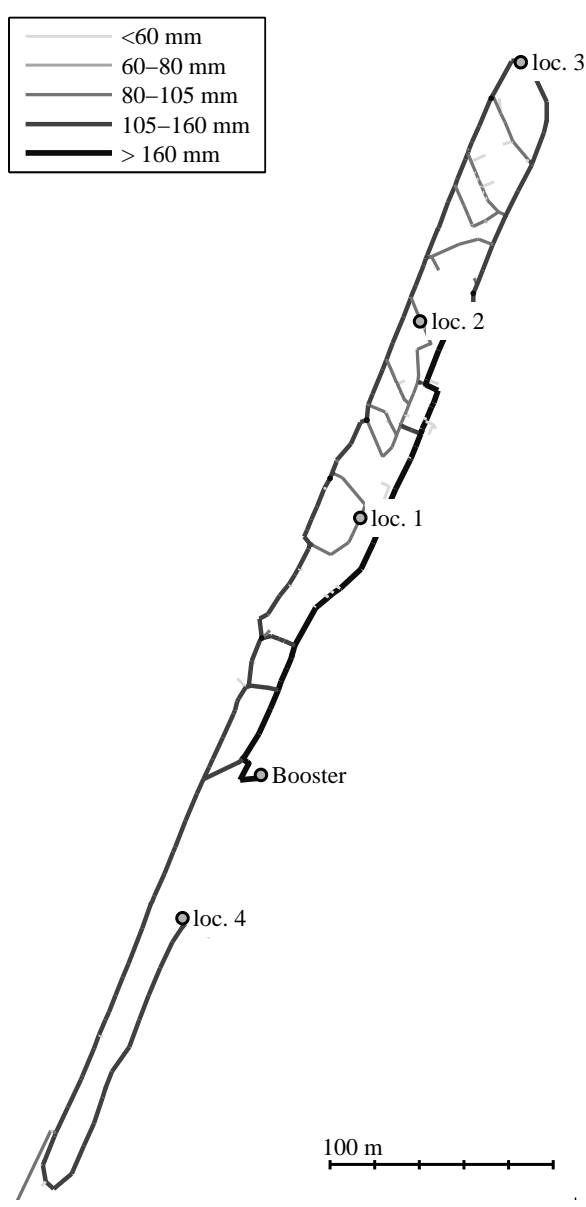

Figure 1. Network layout.

pipes" hydraulic model was constructed with two methods of demand allocation: one with a top-down approach of demand allocation with one unique DMP, and another with a bottomup approach of demand allocation of individual stochastic demand patterns. The model results were compared to the measured flow and water age.

\subsection{The network}

The selected network is situated in the Dutch town Zandvoort, along the sea. The network was built in the 1950 1960 's and consists of $3.5 \mathrm{~km}$ of PVC pipes, and $5.7 \mathrm{~km}$ of lined cast iron pipes (Table 1); it supplies about 1000 homes, 2 hotels and 30 beach clubs (Fig. 1). The area is supplied from one point with a fixed head through a booster pump, there are no tanks in the network. The average travel time is $149.7 \mathrm{~m}^{3} / 24.0 \mathrm{~m}^{3} / \mathrm{h}=6.2 \mathrm{~h}$ (Table 1, Table 2).

The water use in the network was determined from the historic flow patterns at the booster station as measured by the Provincial Water Company Noord-Holland (PWN) and is, on average, $24 \mathrm{~m}^{3} / \mathrm{h}$. Domestic water demand is $70 \%$ of the total demand. As leakage in the Netherlands is generally very low 
Table 2. Demands in Model $_{\mathrm{TD}}$ and $\mathrm{Model}_{\mathrm{BU}}$, \# units with given base demand are reported; these are not all connected to an individual demand node.

\begin{tabular}{|c|c|c|c|c|c|c|c|c|}
\hline \multirow[t]{2}{*}{ Demand category } & \multicolumn{4}{|c|}{ Model $_{\mathrm{TD}}$} & \multicolumn{4}{|c|}{ Model $_{\mathrm{BU}}$} \\
\hline & $\#$ & $\begin{array}{l}\text { base demand } \\
\left(\mathrm{m}^{3} / \mathrm{h}\right)\end{array}$ & $\begin{array}{l}\text { total demand } \\
\qquad\left(\mathrm{m}^{3} / \mathrm{h}\right)\end{array}$ & pattern & $\#$ & $\begin{array}{l}\text { base demand } \\
\qquad\left(\mathrm{m}^{3} / \mathrm{h}\right)\end{array}$ & $\begin{array}{l}\text { total demand } \\
\qquad\left(\mathrm{m}^{3} / \mathrm{h}\right)\end{array}$ & pattern \\
\hline small beach club & 21 & 0.05 & 1.05 & $\mathrm{DMP}_{\text {booster }}$ & 21 & 0.05 & 1.05 & $\mathrm{DMP}_{\text {booster }}$ \\
\hline large beach club & 11 & 0.10 & 1.10 & $\mathrm{DMP}_{\text {booster }}$ & 11 & 0.10 & 1.10 & $\mathrm{DMP}_{\text {booster }}$ \\
\hline residence type A & 100 & 0.015 & 1.50 & $\mathrm{DMP}_{\text {booster }}$ & 869 & N.A. & $10.20-10.60$ & SIMDEUM res. type A \\
\hline residence type B & 210 & 0.02 & 4.20 & $\mathrm{DMP}_{\text {booster }}$ & 210 & N.A. & $3.45-3.75$ & SIMDEUM res. type B \\
\hline apartment building & 25 & $\geq 0.30$ & 10.30 & $\mathrm{DMP}_{\text {booster }}$ & \multirow{2}{*}{\multicolumn{4}{|c|}{ N.A. (moved to residence type A) }} \\
\hline apartment building loc. 4 & 1 & 0.20 & 0.20 & $\mathrm{DMP}_{\text {booster }}$ & & & & \\
\hline NH Hotel, loc. 3 & 1 & 3.247 & 3.247 & $\mathrm{DMP}_{\text {booster }}$ & 1 & $\begin{array}{l}\text { Weibull distributed } \\
(\mathrm{a}=3.247, \mathrm{~b}=4.741)\end{array}$ & $1.73-4.20$ & $\mathrm{DMP}_{\text {hotel }}$ \\
\hline beach hotel Trompstraat & 1 & 1.783 & 1.783 & $\mathrm{DMP}_{\text {booster }}$ & 1 & 1.783 & 1.783 & $\mathrm{DMP}_{\text {hotel }}$ \\
\hline Palacehotel & 1 & 0.50 & 0.50 & $\mathrm{DMP}_{\text {booster }}$ & 1 & 0.50 & 0.50 & $\mathrm{DMP}_{\text {hotel }}$ \\
\hline measurement location & 4 & 0.04 & 0.16 & constant demand & 4 & 0.04 & 0.16 & constant demand \\
\hline Total & & & 24.04 & & & & $20.29-22.40$ & \\
\hline
\end{tabular}

(2-4\%) (Beuken et al., 2006; Geudens, 2008), no leakage is assumed in this network.

The drinking water is distributed without any disinfectant, as is common in the Netherlands. A tracer study with $\mathrm{NaCl}$ was done between 2 September and 20 October 2008.

\subsection{Measurement setup for the tracer study}

The tracer was added at the booster station; in the network, four measurement locations were selected (Fig. 1). Location 1 and location 2 are located near apartment buildings on a $\varnothing 100 \mathrm{~mm}$ PVC and $\varnothing 100 \mathrm{~mm}$ CI pipe. Location 3 is situated in the basement of the hotel. Location 4 is situated in the basement of a small apartment building of 15 residences.

Sodium chloride $(\mathrm{NaCl})$ was used as a tracer and the electrical conductivity was measured. From these measurements, the travel time was determined. $\mathrm{NaCl}$ has several advantages for use as a tracer, viz. at a measurable dosage, it causes no disruption or health risk to customers; it yields results of good accuracy and is low-cost (Skipworth et al., 2002). At the booster location, $\mathrm{NaCl}$ was dosed to a fixed concentration in order to raise the electrical conductivity $(\mathrm{EC}$, in $\mathrm{mS} / \mathrm{m})$ by a measurable amount: $\mathrm{EC} \approx 57 \mathrm{mS} / \mathrm{m}$ without dosage, and $\mathrm{EC} \approx 68 \mathrm{mS} / \mathrm{m}$ with dosage. The tracer was dosed in pulses of $3 \mathrm{~h}$ on and $20 \mathrm{~h}$ off. This means that, per day, one positive and one negative step input were induced. A three hour pulse should be long enough to have a distinctive start and end time at the measurement locations, given the expected dispersion. A $20 \mathrm{~h}$ window of not dosing the tracer ensured that enough $\mathrm{NaCl}$ was available for a 7 week test. The tracer dosing schedule thus shifted the start time of the pulse by $1 \mathrm{~h}$ ever day. Hence, during the seven weeks field study, each hour of the day was used twice as a starting time for the tracer test.

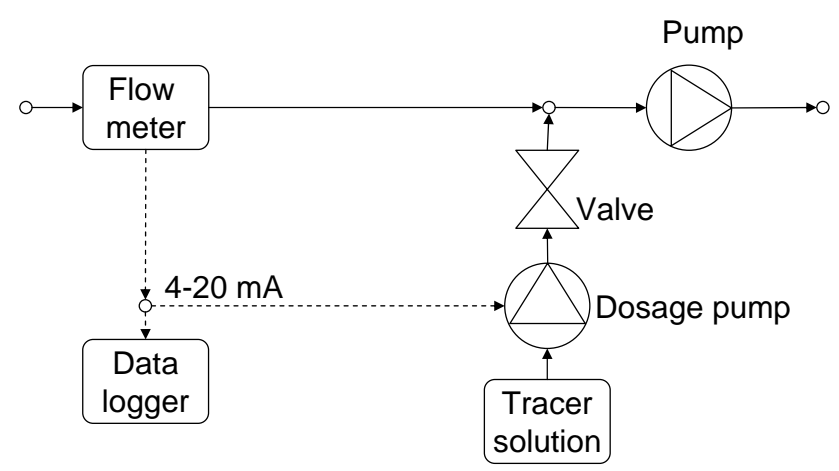

Figure 2. Measurement setup for adding tracer solution.

In order to reach a fixed concentration, the incoming flow was measured (Tokimec UFP-10) and the dosage was controlled (Fig. 2). A solute of $220 \mathrm{~g} / \mathrm{l} \mathrm{NaCl}$ was added with a maximum pump capacity of $201 / \mathrm{h}$ during the maximum demand of $60 \mathrm{~m}^{3} / \mathrm{h}$, and an average dosage capacity of $81 / \mathrm{h}$ during the average demand of $24 \mathrm{~m}^{3} / \mathrm{h}$. This led to a rise of $11 \mathrm{mS} / \mathrm{m}$. Dosage of $3 \mathrm{~h}$ per $23 \mathrm{~h}$ during 50 days means that ca. $275 \mathrm{~kg}$ of $\mathrm{NaCl}$ was used in the tracer test. The booster pumps ensured a constant concentration of the tracer in the water over the pipe, i.e. good mixing, and a fixed head.

The (average) flow was logged every minute for 16 full days of flow measurements at the booster station and 11 full days of flow measurements at location 3 . The time averaged measured flows are denoted $\mathrm{DMP}_{\text {booster }}$ and $\mathrm{DMP}_{\text {hotel }}$. The flow measurements at location 3 showed that the daily demand varied between 2.21 and $4.32 \mathrm{~m}^{3} / \mathrm{h}$ and can be fitted on a Weibull distribution. Based on 11 days, the parameters of the Weibull distribution are estimated at $\mathrm{a}=3.247 \pm 0.4$ and $\mathrm{b}=4.741 \pm 1.7$. 


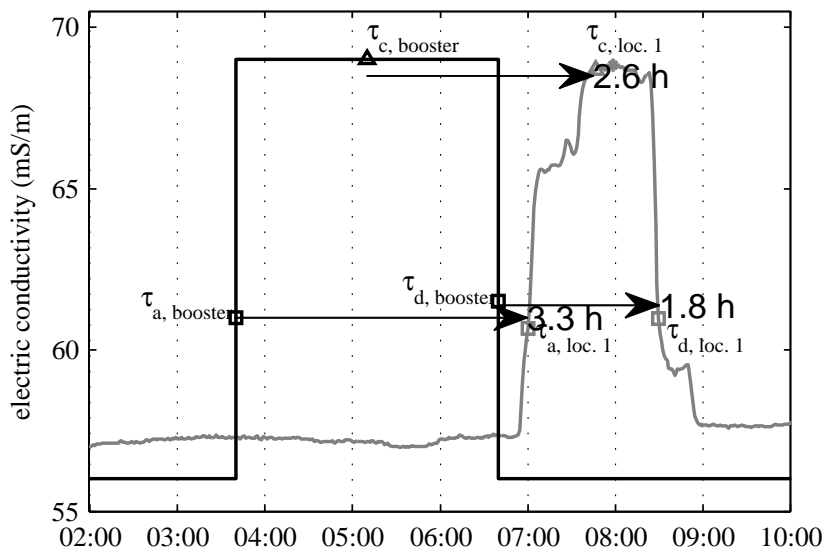

Figure 3. Reconstructed EC at booster locations and measured EC at location 1 (Wednesday, 3 September 2008) plus associated travel times.

At all four locations, the EC was measured (LIQUISYS M CLM223) with an accuracy of $0.1 \mathrm{mS} / \mathrm{m}$. At these locations, the pressure was also measured (3 Endress+Hauser Cerabar VU 130; 1 Endress+Hauser Cerabar M). The measurements required a continuous $40 \mathrm{l} / \mathrm{h}$ extraction. The EC measurement at the booster station was not logged; instead the dosage regime was recorded.

The water age between the booster station and locations 1 , 2, 3 and 4 was determined by the time between the centres of the ascending and descending tails of the EC pulses at around $61 \mathrm{mS} / \mathrm{m}$, which are denote $\tau_{\mathrm{a}}$ and $\tau_{\mathrm{d}}$ respectively, and by the time between the centroids of the pulses, denoted by $\tau_{\mathrm{c}}$. The centroid is determined by the weighted mean between $\tau_{\mathrm{a}}$ and $\tau_{\mathrm{d}}$. Figure 3 shows that at around 07:00 o'clock the travel time between the booster and location 1 was equal to $3.3 \mathrm{~h}$ (ascending tail); at ca. 07:40 the travel time between the booster and location 1 was equal to $2.6 \mathrm{~h}$ (centroid) and at ca. 08:30 the travel time between the booster and location 1 was equal to $1.8 \mathrm{~h}$ (descending tail). The travel time varies over the day and between days. This variation is considered in both the measurements and the hydraulic model.

\subsection{Hydraulic model and demand allocation}

EPANET 2.0 (Rossman, 2000) was used as a hydraulic network model solver. Basically, two models were constructed that are distinguished by demand allocation. Model $_{\mathrm{TD}}$ is the model with the top-down approach of demand allocation; Model $_{\mathrm{BU}}$ is the model with the bottom-up approach of demand allocation.

The measurement locations 1, 2, 3 and 4 were assigned a continuous extraction of $40 \mathrm{l} / \mathrm{h}$. No pressure dependent demands or leaks were introduced in the model. The remaining demand allocation was conducted as follows:

1. In Model $_{\mathrm{TD}}$ an identical DMP (DMP ${ }_{\text {booster, Fig. 4) was }}$ allocated to all demand nodes with a correction factor

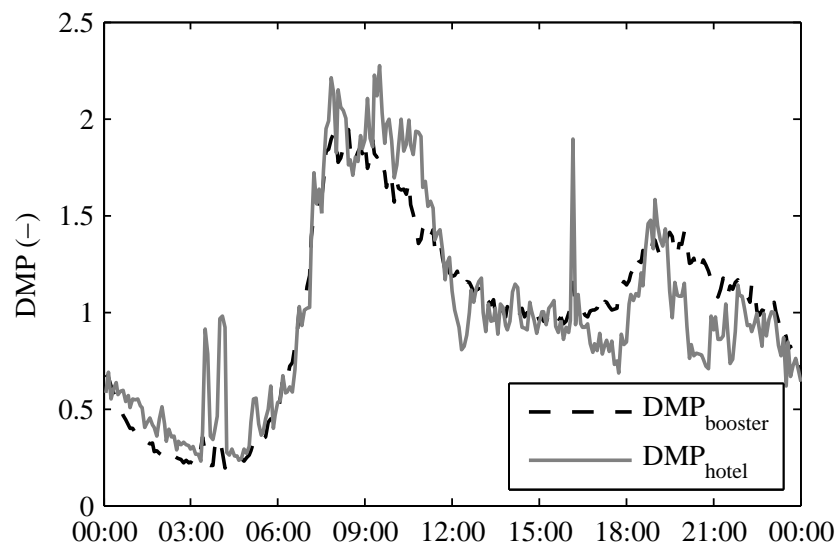

Figure 4. Demand multiplier patterns as used in the Model $_{\mathrm{TD}}$ and Model $_{\mathrm{BU}}$, see Table 2. Measured average demand at booster is $23 \mathrm{~m}^{3} / \mathrm{h}$; measured average demand at hotel is $3 \mathrm{~m}^{3} / \mathrm{h}$.

to account for the average demand. This correction factor is the base demand and it was assigned according to the demand category (Table 2). Because measurement location 4 is a the end of a branch and measurements were done at that apartment building, the apartment building at measurement location 4 was assigned an adjusted base demand. The base demand was calculated for 15 homes of residence type A (15 homes $\times$ 2.3 persons/home $\times 129.3 \mathrm{~L} /$ person.day $\left.\approx 0.2 \mathrm{~m}^{3} / \mathrm{h}\right) . A$ demand node may serve multiple homes or beach clubs.

2. In Model $_{\mathrm{BU}}$ different demand patterns were assigned to different demand category nodes (Table 2).

- To each residential demand node (small and large homes), a unique stochastic water demand pattern was assigned. The stochastic water demand patterns were obtained from the end-use model SIMDEUM (Blokker et al., 2010). Specific data about Zandvoort was used for household composition and water-using appliances (Table 3) as input into SIMDEUM. The type A residences (often apartments, mainly in the north) do not have a garden and no outdoor water use. In the south, type B residences (villas) are found. The census data were not used, because in the measurement period (late summer) it was expected that more people would be occupying the homes than only the inhabitants. For the Model $_{\mathrm{BU}}$ 10, weekday patterns and 4 weekend day patterns were simulated. The residential water use accounts for $68 \%$ of total water use.

- SIMDEUM does not yet provide other than residential demand patterns. To the hotel demand nodes,

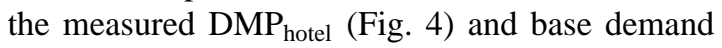
as in the Model $_{\mathrm{TD}}$ were assigned for two hotels; for the hotel at location 3 a base demand according 
Table 3. Specific input data into SIMDEUM; data of Zandvoort Boulevard (1040 homes) in 2003-2007 (CBS).

\begin{tabular}{lllll}
\hline & & $\begin{array}{l}\text { Zandvoort } \\
\text { Boulevard }\end{array}$ & $\begin{array}{l}\text { SIMDEUM residence } \\
\text { type A }\end{array}$ & $\begin{array}{l}\text { SIMDEUM residence } \\
\text { type B }\end{array}$ \\
\hline Households & One person households & $56 \%$ & $34 \%$ & $20 \%$ \\
& Household without children & $34 \%$ & $30 \%$ & $34 \%$ \\
& Household with children & $10 \%$ & $36 \%$ & $46 \%$ \\
& Average household size & 1.6 & 2.3 & 2.7 \\
\hline Age distribution & 0 to 12 years old & $4.8 \%$ & $15 \%$ & $4.8 \%$ \\
& 12 to 21 years old & $3.7 \%$ & $10 \%$ & $3.7 \%$ \\
& 21 to 65 years old & $62.5 \%$ & $63 \%$ & $62.5 \%$ \\
& 65 years and older & $29 \%$ & $12 \%$ & $29 \%$ \\
\hline Water using appliances & WC & & No 6L cisterns & No 6L cisterns \\
& Outside tap & No & Yes, 0.7/day (summer season) \\
\hline Average water use (L per person per day) & & 129.3 & 149.2 \\
\hline
\end{tabular}

to the Weibull distribution was used. Two hotels thus have a deterministic demand pattern; they account for $9.5 \%$ of total water use. The largest hotel, which acocunts for $13.5 \%$ of total demand, has a deterministic demand pattern but a stochasticly determined base demand.

- To the beach club demand nodes, the same $\mathrm{DMP}_{\text {booster }}$ and base demand as in the Model $_{\mathrm{TD}}$ were assigned. The beach clubs have a deterministic demand pattern; they account for $9.0 \%$ of the total water demand.

In EPANET, the hydraulic and pattern time step was set to $15 \mathrm{~min}$ in the Model $_{\mathrm{TD}}$ and to 5 min in the Model $_{\mathrm{BU}}$; the quality time step was set to $1 \mathrm{~min}$ in both models. The common Model $_{\mathrm{TD}}$ uses a time step of $15 \mathrm{~min}$, based on the generally available measurements of a $15 \mathrm{~min}$ time interval. Also, a time step of $15 \mathrm{~min}$ ensures a smooth demand pattern (relatively large auto correlation) which is desired in a top-down approach. For the Model $_{\mathrm{BU}}$ a highly variable demand pattern can occur. Therefore, a shorter time step was used ( $5 \mathrm{~min}$ ). Blokker et al. (2008) have shown that with a time step of 5 min the Reynolds number is most often predicted well compared to a time step of 1 min or less, but a time step of $15 \mathrm{~min}$ leads to deviations. The $\mathrm{DMP}_{\text {booster }}$ and $\mathrm{DMP}_{\text {hotel }}$ were time averaged over $15 \mathrm{~min}$ or $5 \mathrm{~min}$ depending on the used model.

\subsection{Model validation}

The Model $_{\mathrm{TD}}$ was run once and the system flow and water age at four locations were determined. The Model ${ }_{\mathrm{BU}}$ was run 14 times with 14 different sets of stochastic water demand patterns (10 weekdays, 4 weekend days) and 14 different base demands at the NH hotel (location 3). The resulting system flow $\left(\mathrm{Q}_{\mathrm{SIM}}\right)$ is the averaged pattern from the 14 resulting patterns; the resulting water age at the three locations was determined by the average and the $95 \%$ confidence interval of the 14 simulations. This $95 \%$ confidence interval is due to variation, not to uncertainty.

The resulting system flow $\mathrm{Q}_{\text {SIM }}$ was compared with the average measured flows $\mathrm{Q}_{\text {booster }}$ on a time scale of $5 \mathrm{~min}$. The measured water age at four locations and different times of day was compared to the modelled water age in the network. The difference between model and measurement is expressed by the Mean Error (ME), Root Mean Square Error (RMSE), and declaring variance $R^{2}$. The absolute values of ME and RMSE are expressed in hours; the relative values are percentages of the measured travel times. Also, the percentage of the model values that differ less than $10 \mathrm{~min}$ from the measured value is calculated. For the Model $_{\mathrm{TD}}$, this percentage is calculated for the average modelled values. For the Model $_{\mathrm{BU}}$, this percentage is calculated for the average modelled values and for the total of the 14 different runs.

\section{Results}

\subsection{Demand multiplier pattern}

The modelled and measured flow patterns at the booster station were compared. By looking at the diurnal pattern we can get a feel for how well the model resembles reality. To quantify the resemblance, the auto- and cross-correlation of the flow patterns were considered. The cross-correlation between the flow patterns shows how well the modelled flow patterns fit the measured flow patterns; cross-correlation can be established for different time lags, which shows if the modelled flow patterns exhibit a delay with respect to the measured flow patterns. The auto-correlation of the flow patterns shows how variable the flow patterns are. 


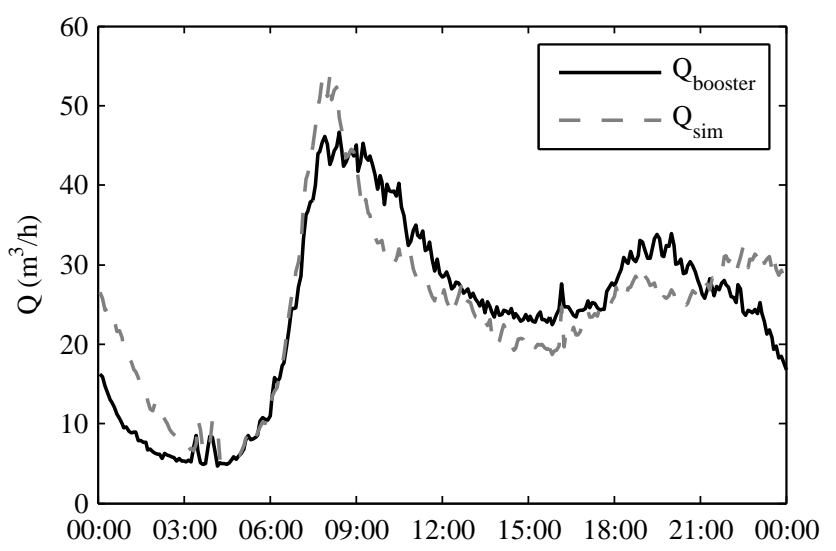

Figure 5. Measured $\left(\mathrm{Q}_{\text {booster }}\right)$ and simulated $\left(\mathrm{Q}_{\mathrm{SIM}}\right.$ from $\left.\operatorname{Model}_{\mathrm{BU}}\right)$ flows on a 5 -min time scale.

Figure 5 shows the diurnal pattern. The modelled flow pattern has a more distinct morning peak than the measured pattern. The simulated pattern shows a later decline to low night use than the measured flow. The small peaks around 04:00 a.m. are due only to the hotel's demands. The modelled flow shows these peaks because the beach clubs have them in the applied $\mathrm{DMP}_{\text {booster }}$ and the hotels have them in the applied $\mathrm{DMP}_{\text {hotel }}$. These two peaks were most likely related to cleaning. A further analysis showed that the modelled flow pattern has a smaller auto-correlation than the measured flow pattern. The cross-correlation between $\mathrm{Q}_{\text {booster }}$ and $\mathrm{Q}_{\mathrm{SIM}}$ is 0.9 at a time lag of 0, i.e. there is no delay. The morning peak of $\mathrm{Q}_{\mathrm{SIM}}$ coincides with the morning

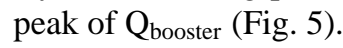

\subsection{Water age}

At locations 1, 2 and 4 the measured EC resembles the rectangular pulse at the booster station and the centres of the ascending and descending tails and the weighted means between those centres can easily be determined (Fig. 6). Each pulse at the booster station led to 3 measured travel times at those locations, 138 measurement points in total at each location. At location 3, the pulse changed shape due to mixing and dispersion, and often more than one pulse can be seen (Fig. 6). The travel time can only be determined at the ascending tail of the pulse. Each pulse at the booster station led to 1 measured travel time at location 3, 46 measurement points in total.

The EC-pulse leaving the booster station at Thursday, 4 September (between 02:40 and 05:40) led to the EC-pulses of Fig. 6 at locations 1, 2 and 3. The EC-pulse leaving the booster station at Wednesday, 3 September (between 03:40 and 06:40) led to the EC-pulses of Fig. 6 at location 4. The maximum EC at Wednesday was higher than at Thursday. The maximum EC at location 4 is always slightly lower than

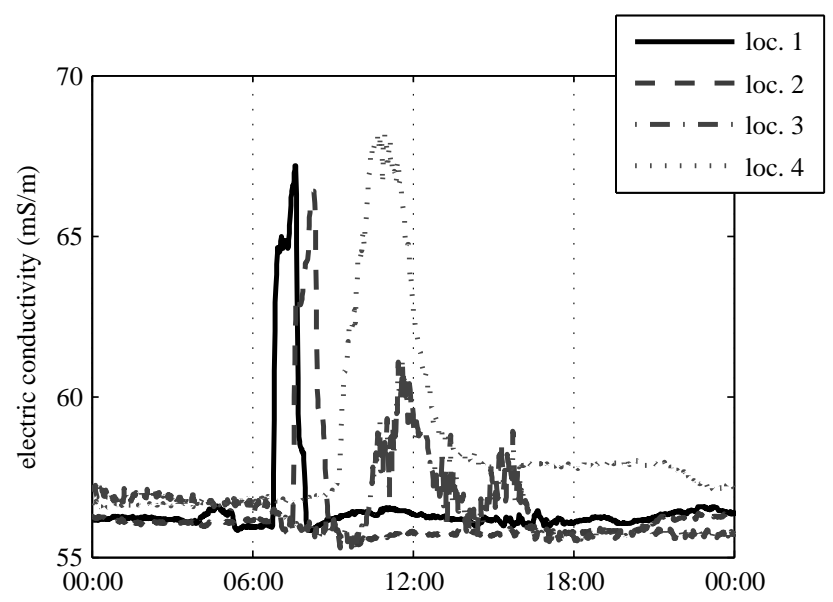

Figure 6. Measured EC at locations 1-4 at Thursday, 4 September 2008. The EC at location 4 has a $24 \mathrm{~h}$ delay and is connected to the pulse that left the booster station at Wednesday, 3 September 2008 .

at locations 1 and 2; the EC-pulse at location 4 is always much wider. This means that dispersion occurs at location 4.

Figure 7 shows the measured and modelled water age over the day at the four measurement locations; Table 4 summarises the statistics. Depending on the network layout and the measurement location, the maximum water age is reached around 07:00 a.m., which is related to low night use. The fast decrease in water age after the maximum is related to the peak in demand in the morning. The $95 \%$ confidence interval of the water age in the Model $_{\mathrm{BU}}$ is the largest for location 4 in the looped network layout because there are only 15 homes present behind the measurement location. The individual behaviour of the people in those homes has a large effect on demand and thus on travel time.

The average and $95 \%$ confidence interval of the water age from the Model $_{\mathrm{BU}}$ and the water age from the Model $_{\mathrm{TD}}$ with $\mathrm{DMP}_{\text {booster }}$ were compared with the measured water ages. The two models predict the water age well, with an ME and RMSE of less than $30 \%$. The Model $_{\mathrm{BU}}$ shows lower ME and RMSE than the Model $_{\mathrm{TD}}$. The $95 \%$ confidence interval of the Model $_{\mathrm{BU}}$ presents much more data points within $10 \mathrm{~min}$ from the measured water age than the average of both the Model $_{\mathrm{BU}}$ and the Model $\mathrm{TD}$. The calculated $R^{2}$ is not a meaningful value for either model, and therefore it is not shown in the table.

\section{Discussion}

A tracer test was done in an intermediate scale DWDS. As $30 \%$ of the pipes experience laminar flow for more than $50 \%$ of the time, dispersion is an issue in this network. In the pipes leading to location 4, flows are laminar during most of the day. In these laminar flow pipes, the travel time is approximately $24 \mathrm{~h}$. In the part of the network around location 3 , 

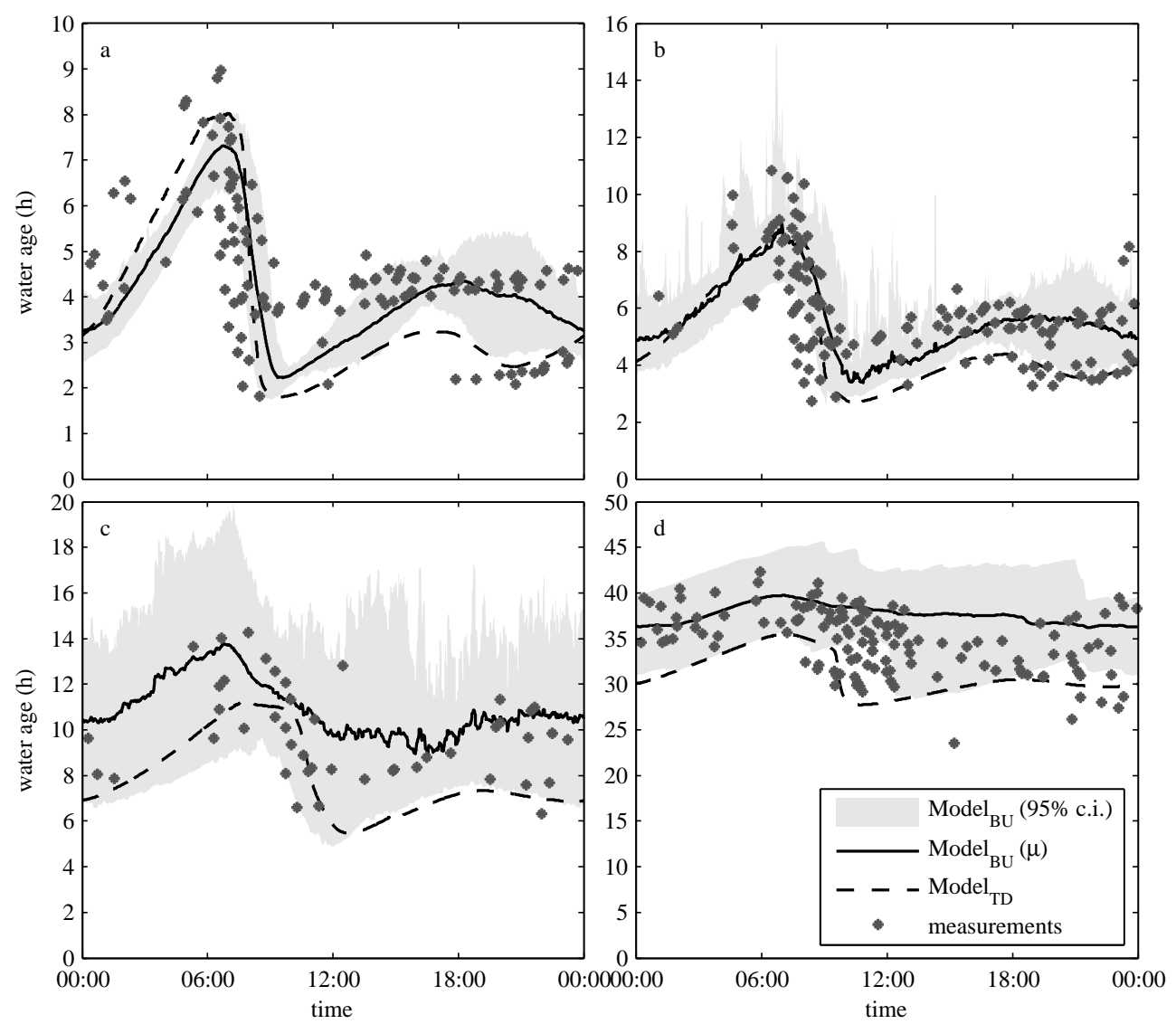

Figure 7. Measured and modelled water age at location (a) 1; (b) 2; (c) 3 and (d) 4. N.B. the 95\% confidence interval is due to variation, not to uncertainty.

Table 4. Average absolute and relative differences between measured and modelled water age.

\begin{tabular}{llrrrr|rrrr}
\hline & & \multicolumn{4}{c}{ Model $_{\mathrm{BU}}$} & \multicolumn{4}{c}{ Model $_{\mathrm{TD}}$} \\
\cline { 3 - 9 } & & loc. 1 & loc. 2 & loc. 3 & loc. 4 & loc. 1 & loc. 2 & loc. 3 & loc. 4 \\
\hline Sample size & & 126 & 138 & 46 & 135 & 126 & 138 & 46 & 135 \\
ME & absolute (h) & -0.14 & -0.06 & 0.17 & 2.06 & -0.27 & -0.48 & -1.45 & -4.41 \\
& relative (\%) & -3.14 & -0.99 & 1.76 & 5.91 & -5.89 & -8.23 & -14.73 & -12.63 \\
RMSE & absolute (h) & 1.42 & 1.42 & 1.65 & 4.05 & 1.85 & 1.77 & 2.47 & 5.68 \\
& relative (\%) & 31.09 & 24.08 & 16.83 & 11.61 & 40.50 & 30.18 & 25.17 & 16.28 \\
Within 10 min & Compared to mean & 9.52 & 7.97 & 13.04 & 0.74 & 3.97 & 14.49 & 0 & 0.74 \\
deviation (\%) & Compared to 95\% c.i. & 64.29 & 79.71 & 100.0 & 77.78 & N.A. & N.A. & N.A. & N.A. \\
\hline
\end{tabular}

the flows are also mainly laminar. Figure 6 shows dispersion for both location 3 and location 4 . As the water age was derived from the $\mathrm{NaCl}$ pulse, the measured water age includes dispersion. When the measured water age is compared to model results, the model should also incorporate dispersion. It would be interesting to validate an advection-dispersionreaction model (Tzatchkov et al., 2002; Li et al., 2006) in this network.
For this area, an "all pipes" hydraulic model was constructed with two methods of demand allocation: one with a top-down approach of demand allocation with a common DMP and another with a bottom-up approach of demand allocation of individual and unique stochastic demand patterns. It is possible to construct accurate water demand patterns with the end-use model SIMDEUM. In this paper the flow pattern as measured in an area of 1000 homes $\left(\mathrm{Q}_{\text {booster }}\right)$ was compared with the flow pattern from the simulated water 
demand patterns of the model ( $\left.\mathrm{Q}_{\text {SIM }}\right)$. The $\mathrm{Q}_{\text {SIM }}$ fit the $\mathrm{Q}_{\text {booster }}$ well with a cross-correlation of almost $90 \%$.

The night use of the simulated flows closely matched the measured flows. This indicates a very low leakage in this network. The hotels and beach clubs did not have a residential demand pattern assigned to them; instead, measured DMP were used. The beach clubs had an average demand of $9 \%$ of the total system demand; the average demand of the hotels is $23 \%$ of the total demand. It would be an asset if SIMDEUM could be extended to not only simulate residential water demand, but also the demand by hotels, for example.

It is possible to construct a water age model with accurate water demand patterns using the bottom-up approach without the need for calibration on demands. The Model ${ }_{\mathrm{BU}}$ predicts the average water age slightly better than the Model $\mathrm{TD}_{\mathrm{TD}}$. The Model $_{\mathrm{BU}}$ provides information on the variability of the water age, and thus the $95 \%$ confidence interval of the Model $_{\mathrm{BU}}$ leads to better predictions of the water age than the Model $_{\mathrm{TD}}$ does. With the top-down approach it is also possible to introduce variability; based on two weeks of flow measurements 14 different DMP and 14 corresponding day factors (with values between 0.9 and 1.3) were imposed (Blokker and Beverloo, 2009). This resulted in a narrow 95\% confidence interval around the mean. This improved ME, and RMSE slightly, but the Model $_{\mathrm{BU}}$ still performed better (data not shown).

Both models resulted in similar flow patterns at the booster station and similar water ages at the demand nodes The Model $l_{\mathrm{BU}}$ predicts the water age only slightly better than the Model $_{\mathrm{TD}}$. The models had more distinct results with respect to flow direction reversals during the day and maximum instantaneous flow velocities (Blokker and Beverloo, 2009). The Model $_{\mathrm{BU}}$ showed a flow direction reversal in $30 \%$ of the pipes; the Model $\mathrm{TD}_{\mathrm{TD}}$ showed it for only $15 \%$ of the pipes. The Model $_{\mathrm{BU}}$ resulted in $75 \%$ of the pipes with a higher flow velocity than in the Model $\mathrm{T}_{\mathrm{T}}$, on average flow velocities were $25 \%$ higher. In $12 \%$ of the pipes, the Model $_{\mathrm{BU}}$ resulted in a higher flow regime (turbulent or transitional flow, rather than laminar flow). These differences between the two models will affect water quality modelling where dispersion is significant, such as in the case of dissolved substances.

The pulse shape of the $\mathrm{NaCl}$ varies a lot between days, especially at measurement location 3 . Water reaches location 3 via the pipes east of the connection pipe and via the west. Depending on the water use, which differs over the day and between days, the received $\mathrm{NaCl}$ may appear as more than one pulse (Fig. 6). Because at each day the pulse leaves the booster station at a different time of the day, each measurement day shows different results. The Model ${ }_{\mathrm{TD}}$ never results in split pulses at location 3. The Model $_{\mathrm{BU}}$, however, resulted for 1 out of 10 simulation runs in split pulses for the pulse of 14 October (Fig. 8). A proper demand allocation will therefore lead to better predictions of pulse shape.

The stochastic approach of hydraulic modelling gives insight into the variability of travel times as an added feature

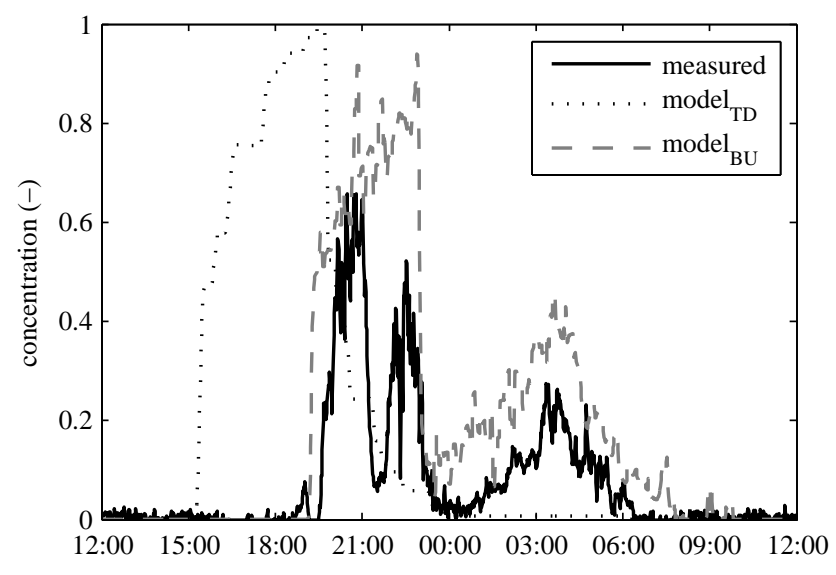

Figure 8. Measured and modelled pulses at measurement location 3 at 14-15 October 2008.

beyond the conventional way of modelling. The conventional Model $_{\mathrm{TD}}$ has a higher auto- and cross-correlation of flows than the actual flows in the network. This results in the Model $_{\mathrm{TD}}$ underestimating the flow direction reversals, stagnant flows and thus maximum travel times. Because Machell et al. (2009) have argued that the maximum travel time is much more important than the average travel time, the Model $_{\mathrm{BU}}$ has benefits in determining water age.

The bottom-up modelling approach is probabilistic in nature and offers a new perspective for assessing water quality in the drinking water distribution system. In the case presented, it shows that, especially at location 4 , the variability is very high. Calibration of the top-down model of Zandvoort was attempted (Pardo Picazo, 2009). However, calibration on pressure appeared to be impossible due to small head losses. Calibration of demands on the tracer measurements appeared to be difficult because the demand was so variable.

\section{Conclusions}

A bottom-up approach of demand allocation (i.e. water demand patterns are modelled per individual home and subsequently the individual water demand patterns are summed to obtain the water demand patterns at demand nodes) leads to a total flow that is at least as good as the flow from the commonly used top-down approach. The individual demand patterns are obtained from the end-use model SIMDEUM without the need for any flow measurements. Some specific census data was collected and used as input to SIMDEUM; most of the input data can be re-used from earlier studies.

A bottom-up approach leads to good results in predicting water age in an intermediate scaled DWDS. There is no need for measuring water demand patterns, nor for calibration of demand based on water quality parameters.

The water demand patterns are constructed per individual home and on a per second basis. For the purpose of water 
age prediction it is acceptable to use time-averaging, and use a hydraulic time step of $5 \mathrm{~min}$.

A stochastic approach in demand and water quality modelling results in more insight into the variability of travel times. A detailed demand allocation with stochastic demand patterns will improve the water quality modelling, especially in the periphery of the drinking water distribution system.

Edited by: L. Rietveld

\section{References}

Beuken, R. H. S., Lavooij, C. S. W., Bosch, A., and Schaap, P. G.: Low leakage in the Netherlands confirmed, Water Distribution System Analysis \#8, Cincinnati, Ohio, USA, 27-30 August 2006, 2006.

Blokker, E. J. M., Vreeburg, J. H. G., Buchberger, S. G., and van Dijk, J. C.: Importance of demand modelling in network water quality models: a review, Drink. Water Eng. Sci., 1, 27-38, 2008, http://www.drink-water-eng-sci.net/1/27/2008/.

Blokker, E. J. M. and Beverloo, H.: Verblijftijden leidingnet Zandvoort; Metingen boulevard Zandvoort zomer 2008 (Residence times in distribution net Zandvoort; Measurements boulevard Zandvoort summer 2008), KWR, Nieuwegein, 2009 (in Dutch).

Blokker, E. J. M., Vreeburg, J. H. G., and van Dijk, J. C.: Simulating residential water demand with a stochastic end-use model, J. Water Res. Pl.-ASCE, 136, 19-26, 10.1061/(ASCE)WR.19435452.0000002, 2010.

CBS: http://statline.cbs.nl, last access: July 2008.

EPA: Effects of water age on distribution system water quality, prepared by AWWA with assistance from Economic and Engineering Services, Inc., 2002.
Geudens, P. J. J. G.: Water supply statistics 2007, Vewin, Rijswijk, 2008.

Li, Z., Buchberger, S. G., and Tzatchkov, V. G.: Integrating distribution network models with stochastic water demands and mass dispersion, Water Distribution System Analysis \#8, Cincinnati, Ohio, USA, 27-30 August 2006.

Machell, J., Boxall, J., Saul, A., and Bramley, D.: Improved Representation of Water Age in Distribution Networks to Inform Water Quality, J. Water Res. Pl.-ASCE, 135, 382-391, 2009.

Pardo Picazo, M. A.: Water quality model calibration using the $\mathrm{NaCl}$ tracer test, M.Sc., Instituto tecnológico del Agua, Universidad Politénica de Valencia, Valencia, Spain, 68 pp., 2009.

Powell, J., Clement, J., Brandt, M., R, C., Holt, D., Grayman, W., and LeChevallier, M.: Predictive Models for Water Quality in Distribution Systems, AWWARF, Denver, Colorado, USA, 2004.

Rossman, L. A.: EPANET 2 user manual, United States Environmental Protection Agency, Cincinnati, 2000.

Skipworth, P. J., Machell, J., and Saul, A. J.: Empirical travel time estimation in a distribution network, Water \& Maritime Engineering, 154, 41-49, 2002.

Slaats, P. G. G., Rosenthal, L. P. M., Siegers, W. G., van den Boomen, M., Beuken, R. H. S., and Vreeburg, J. H. G.: Processes involved in the generation of discolored water, AWWARF, Denver, Co, USA, 2003.

Tzatchkov, V. G., Aldama, A. A., and Arreguin, F. I.: Advectiondispersion-reaction modeling in water distribution networks, J. Water Res. Pl.-ASCE, 131, 334-342, 2002.

Vreeburg, J. H. G.: Discolouration in drinking water systems: a particular approach, 183 pp., 2007.

Vreeburg, J. H. G. and Boxall, J. B.: Discolouration in potable water distribution systems: A review, Water Res., 41, 519-529, 2007. 